\title{
ESTIMATIVAS DE INVESTIMENTOS EM PLANOS MUNICIPAIS DE SANEAMENTO BÁSICO: UMA ANÁLISE CRÍTICA
}

\section{INVESTMENT ESTIMATES IN MUNICIPAL PLANS OF BASIC SANITATION: A CRITICAL ANALYSIS}

\section{Carolina Rodeiro Nunes}

Mestranda em Meio Ambiente, Águas e Saneamento. Universidade Federal da Bahia / Escola Politécnica. (carol.rodeiro@hotmail.com)

\section{Patrícia Campos Borja}

Doutora em Arquitetura e Urbanismo. Universidade Federal da Bahia / Departamento de Engenharia Ambiental e Mestrado em Meio Ambiente, Águas e Saneamento. (borja@ufba.br)

\section{Resumo}

Estudou-se a metodologia empregada nas estimativas de investimentos dos Planos Municipais de Saneamento Básico (PMSB) de municípios brasileiros. Foram avaliados 25 PMSB com base em seis critérios validados e hierarquizados por especialistas, a saber: detalhamento das ações dos projetos propostos, coerência das referências empregadas, consistência metodológica, descrição e coerência dos investimentos ao longo do horizonte de planejamento, delineamento dos investimentos por componente do saneamento básico e detalhamento das fontes de financiamento. Os critérios possibilitaram calcular um Índice de Conformidade (IC) para cada Plano e classificá-los como ruim, regular, bom e excelente. Conforme os resultados, $68 \%$ dos planos foram classificados como ruins, $28 \%$ como regulares, $4 \%$ como bons e nenhum obteve qualificação excelente. Identificou-se que a projeção de investimentos dos PMSB apresenta debilidades importantes que irão impactar a implementação dos planos e o alcance das metas de universalização dos serviços. As debilidades dos municípios quanto a recursos e capacidade técnicoinstitucional explicam, em parte, essa realidade.

Palavras-chave: PMSB; estimativas de investimentos; debilidades.

\section{Abstract}

An analysis of the methodology used in the estimations of investments for the Municipal Plans of Basic Sanitation (PMSB) in Brazilian municipalities was carried out. 25 PMSB were evaluated, based on six criteria validated and ranked by specialists. The criteria considered in the analysis, according to the resulting hierarchy, were: details of the actions for the proposed projects, consistency of the references used, methodological consistency, description and coherence of investments throughout the planning horizon, design of basic sanitation investments and details of sources to investment financing. The criteria integrate a mathematical expression, the Conformity Index $(\mathrm{Cl})$, on what, from the achieved score the plans, they were classified in the categories: bad, regular, good and excellent. Results showed unsatisfactory performance: $68 \%$ classified as bad, $28 \%$ as regular, $4 \%$ as good and just none as excellent. The projection of investments presents important weaknesses that will affect the implementation of the plans and the achievement of the universalization goals. Such reality is partially explained by weaknesses of Brazilian municipalities regarding financial resources and technical and institutional capacity.

Key-words: sanitation plan; investment estimates; weaknesses.

\section{INTRODUÇÃO}

A promulgação da Lei $n^{\circ} 11.445 / 2007$ definiu novas atribuições aos municípios, titulares dos serviços públicos de saneamento básico, como, por exemplo, a elaboração do Plano Municipal de
Saneamento Básico (PMSB) e a formulação da Política Municipal de Saneamento Básico. A gestão dos serviços passa, então, a englobar o conjunto das atividades envolvidas no planejamento, na prestação, na regulação e na fiscalização, sendo todas elas submetidas à 
participação e ao controle social. Além disso, o saneamento básico passa a ser orientado por princípios fundamentais, entre eles a universalização do acesso, a integralidade entre as componentes do saneamento básico, a utilização de tecnologias apropriadas à realidade local, a segurança, qualidade e regularidade e 0 controle social (BRASIL, 2007).

A etapa de planejamento, embora fundamental para o desenvolvimento das outras atividades de gestão dos serviços públicos de saneamento básico ${ }^{1}$, tem sido subestimada, mesmo após a obrigatoriedade da elaboração do PMSB ter sido definida na Lei $n^{\circ} 11.445 / 2007$. Nos termos da Lei, a elaboração do PMSB é atividade integrante da Política Municipal de Saneamento Básico, para o acesso a recursos do governo federal para investimentos na área, para a validação de contratos de prestação dos serviços e, principalmente, para orientar os municípios no processo de universalização dos serviços.

Apesar da suma importância desse instrumento da gestão municipal ao alcance da universalização do acesso aos serviços, o mesmo ainda encontra obstáculos significativos para sua elaboração. O levantamento realizado no âmbito da Pesquisa de Informações Básicas Municipais (MUNIC) mostrou que apenas $14 \%$ dos municípios brasileiros possuíam PMSB no ano de 2013.

Dentre as dificuldades enfrentadas pelos municípios estão: o desconhecimento das obrigações dos titulares dos serviços quanto à política de saneamento básico, a pouca disponibilidade de recursos financeiros, a falta de capacitação técnica ou quadro de funcionários para elaboração, participação e acompanhamento do PMSB, limitações nos processos de mobilização e participação social, falta de comprometimento dos gestores, dentre outras.

A qualidade dos planos elaborados também demonstra certo despreparo ou mesmo descaso por parte dos gestores municipais, da sua equipe elaboradora e dos órgãos fiscalizadores. O estudo desenvolvido por Pereira (2012), que visou avaliar o conteúdo e metodologia de 18 PMSB de municípios brasileiros, constatou

Saneamento básico entendido como o conjunto dos serviços públicos de abastecimento de água, esgotamento sanitário, drenagem urbana e manejo de águas pluviais e limpeza urbana e manejo de resíduos sólidos fragilidade na implantação da política municipal de saneamento básico e na incorporação dos princípios fundamentais previstos no marco legal no conteúdo dos planos. Dessa forma, a qualidade da elaboração dos PMSB e sua influência na conquista da universalização do acesso aos serviços públicos de saneamento básico são colocadas em debate.

A realização das estimativas de investimentos para a execução das intervenções em saneamento básico compõe uma das etapas da elaboração do PMSB. Essa etapa, que se constitui em um dos documentos integrantes do Plano, visa definir os custos envolvidos na execução de cada programa, projeto e ação definidos no PMSB, as estratégias de alocação e captação de recursos por parte dos municípios, bem como as definições sobre as instituições executoras, parceiras e instituições financiadoras. Dessa forma, as estimativas de investimentos para as intervenções na área de saneamento básico visam assegurar a plena execução do PMSB, integrando, inclusive, uma parte do documento que define os investimentos necessários para 0 desenvolvimento dos objetivos e metas previstos, tanto por meio de dotação orçamentária, cobrança de taxas e tarifas, como também via captação de recursos financeiros.

Apesar da sua importância para a adequada implementação do PMSB, as estimativas de investimentos têm sido realizadas a partir de critérios e metodologias diferenciadas e, por vezes, inconsistentes, que variam não apenas de acordo com a fonte financiadora do PMSB, mas também com o nível de fiscalização durante 0 processo de elaboração.

Assim, existe a necessidade de se promover uma análise das metodologias adotadas para as estimativas de investimentos apresentadas nos PMSB já aprovados, de forma a identificar as inconsistências e/ou pertinências com vistas a qualificar os processos de elaboração dos PMSB.

\section{OBJETIVOS}

\section{Objetivo geral}

- Realizar uma análise crítica da metodologia empregada nas estimativas de investimentos de planos municipais de saneamento básico de municípios brasileiros. 


\section{Objetivos específicos}

- Definir critérios para avaliação da metodologia empregada nas estimativas de investimentos de planos municipais de saneamento básico.

- Identificar e relacionar inconsistências metodológicas em processos de estimativas de investimentos de planos municipais de saneamento básico.

- Avaliar e comparar as metodologias de estimativas de investimentos de planos de diferentes municípios brasileiros.

\section{MATERIAIS E MÉTODOS}

A avaliação e comparação da metodologia empregada nas estimativas de investimentos, para a execução das ações dos Planos Municipais de Saneamento Básico (PMSB), foi realizada junto a 25 planos elaborados no Brasil por meio da construção e aplicação de um Índice de Conformidade (IC), inspirados em Baracho (2015). Os planos analisados foram obtidos por meio da cooperação da Funasa e de pesquisas em sites oficiais de prefeituras. A seleção buscou abranger municípios de todas as regiões brasileiras, objetivando realizar uma análise da situação nacional à luz do tema em estudo.

O estudo contemplou a análise de PMSB e de planos setoriais de abastecimento de água e esgotamento sanitário e, também, de planos envolvendo estes componentes, bem como a drenagem das águas pluviais, sendo as análises realizadas a partir dos mesmos procedimentos. Ressalta-se que essa diferenciação de tipos de planos não acarreta em prejuízo aos resultados do tema em estudo.

Para a construção do Índice de Conformidade (IC), foram pré-selecionados seis critérios entendidos como essenciais para essa análise, sendo eles: detalhamento das ações propostas (CR1), coerência e adequabilidade das referências empregadas nas estimativas de investimentos (CR2), consistência metodológica empregada nas estimativas dos investimentos (CR3), descrição e coerência dos investimentos ao longo do horizonte de planejamento (CR4), delineamento dos investimentos por componente do saneamento básico (CR5) e detalhamento das fontes de financiamento dos investimentos propostos (CR6). A seleção dos critérios foi baseada no seu impacto na adequada execução das intervenções propostas nos planos pelos gestores. A escolha dos critérios foi norteada pela pesquisa bibliográfica sobre o tema $\mathrm{e}$, ainda, pela vivência adquirida na elaboração de PMSB. O Quadro 1 apresenta e detalha a pertinência de cada critério.

Objetivando validar e hierarquizar os critérios para a construção do Índice de Conformidade das estimativas dos investimentos dos planos, fez-se uma consulta a uma rede de especialistas (SKULMOSKI; HARTMAN; KRAHN, 2007; MUNARETTO; CORRÊA; CUNHA, 2013). Foram escolhidos profissionais com experiência na elaboração e/ou revisão de Planos Municipais de Saneamento Básico, visando, assim, maior confiabilidade dos resultados.

O convite para integrar o grupo de especialistas foi realizado com envio de e-mail a cada um dos participantes, juntamente com o link para acesso e preenchimento online do formulário da pesquisa. A construção do formulário a e realização da consulta foram feitas pela ferramenta Google Forms.

O Quadro 1 foi disponibilizado no formulário online para fins de esclarecimento a respeito de cada critério sugerido. Com isso, foi solicitado aos especialistas consultados que cada critério fosse hierarquizado com base na sua importância para a realização das estimativas de investimentos, sendo 1 atribuído para o critério mais impactante, avançando na escala até a importância de 6 , destinado para o critério menos impactante. Foi dada a possibilidade, ainda, de atribuir a classificação de "Não deve fazer parte", para sinalizar a exclusão de algum critério.

Vale ressaltar que como o intuito da pesquisa se referia à obtenção da hierarquização e validação dos critérios, cada ponderação dentro da escala adotada somente poderia ser atribuída a apenas um dos critérios, sem a possibilidade de critérios distintos obterem a mesma pontuação. Com base na hierarquização dos critérios obtida por meio da consulta aos especialistas, foram estipulados pesos para cada critério e formulada uma expressão matemática para representar o Índice de Conformidade (IC), demonstrada na Equação 1. 


\section{Quadro 1 - Critérios propostos para análise da metodologia empregada na estimativa de investimentos dos PMSB}

\begin{tabular}{|c|c|c|c|}
\hline Critérios & Importância & Avaliação do critério & $\begin{array}{l}\text { Impacto do não } \\
\text { atendimento }\end{array}$ \\
\hline $\begin{array}{l}\text { Detalhamento } \\
\text { das ações } \\
\text { propostas } \\
\text { (CR1) }\end{array}$ & $\begin{array}{c}\text { Nortear os gestores } \\
\text { na execução das } \\
\text { ações de maneira } \\
\text { adequada e direcionar } \\
\text { as estimativas dos } \\
\text { custos. }\end{array}$ & $\begin{array}{c}\text { Verificar se as ações } \\
\text { propostas são descritas com } \\
\text { um nível de detalhamento } \\
\text { que permita atingir os } \\
\text { objetivos dos } \\
\text { projetos/programas } \\
\text { propostos. }\end{array}$ & $\begin{array}{l}\text { Projetos que não } \\
\text { atingem seus objetivos e } \\
\text { metas devido à } \\
\text { implementação } \\
\text { equivocada das ações. }\end{array}$ \\
\hline $\begin{array}{c}\text { Coerência e } \\
\text { adequabilidade } \\
\text { das } \\
\text { referências } \\
\text { empregadas } \\
\text { nas } \\
\text { estimativas } \\
\text { (CR2) }\end{array}$ & $\begin{array}{c}\text { Dar credibilidade ao } \\
\text { valor estimado para } \\
\text { cada } \\
\text { ação/projeto/programa } \\
\text { através do uso de } \\
\text { referências de fontes } \\
\text { confiáveis e } \\
\text { adequadas à } \\
\text { realidade local. }\end{array}$ & $\begin{array}{l}\text { Analisar se as referências } \\
\text { empregadas nas estimativas } \\
\text { são confiáveis, com relação à } \\
\text { fonte da informação, e se são } \\
\text { adequadas à realidade local. }\end{array}$ & $\begin{array}{l}\text { Valores estimados não } \\
\text { estarem de acordo com } \\
\text { a realidade local, } \\
\text { impossibilitando a plena } \\
\text { execução do PMSB. }\end{array}$ \\
\hline $\begin{array}{l}\text { Consistência } \\
\text { metodológica } \\
\text { empregada } \\
\text { nas } \\
\text { estimativas } \\
\text { dos custos } \\
\text { (CR3) }\end{array}$ & $\begin{array}{l}\text { Dar credibilidade ao } \\
\text { valor estimado para } \\
\text { os gestores e para } \\
\text { todos os membros da } \\
\text { sociedade civil que } \\
\text { busquem a leitura do } \\
\text { Plano. }\end{array}$ & $\begin{array}{c}\text { Avaliar as ponderações } \\
\text { empregadas no cálculo das } \\
\text { estimativas das ações, ou } \\
\text { seja, avaliação da } \\
\text { consistência do memorial de } \\
\text { cálculo, das ponderações } \\
\text { empregadas, dos custos } \\
\text { unitários levantados e dos } \\
\text { dados municipais. }\end{array}$ & $\begin{array}{l}\text { Investimento estimado } \\
\text { não estar de acordo com } \\
\text { a realidade, dificultando } \\
\text { ou mesmo } \\
\text { impossibilitando a sua } \\
\text { implementação. }\end{array}$ \\
\hline $\begin{array}{l}\text { Descrição e } \\
\text { coerência dos } \\
\text { investimentos } \\
\text { ao longo do } \\
\text { horizonte de } \\
\text { planejamento } \\
\text { (CR4) }\end{array}$ & $\begin{array}{l}\text { Influência direta no } \\
\text { planejamento dos } \\
\text { gastos públicos e na } \\
\text { correta execução das } \\
\text { ações. }\end{array}$ & $\begin{array}{l}\text { Analisar a conformidade do } \\
\text { intervalo de tempo proposto } \\
\text { para execução de cada } \\
\text { ação/projeto/programa, } \\
\text { considerando possíveis } \\
\text { interconexões existentes } \\
\text { entre ações. }\end{array}$ & $\begin{array}{c}\text { Implementação de } \\
\text { ações sem respeito à } \\
\text { hierarquização } \\
\text { necessária, } \\
\text { prejudicando a } \\
\text { execução do PMSB, } \\
\text { além de dificultar a } \\
\text { alocação dos gastos } \\
\text { públicos pelos gestores. }\end{array}$ \\
\hline $\begin{array}{c}\text { Delineamento } \\
\text { dos } \\
\text { investimentos } \\
\text { por } \\
\text { componente } \\
\text { do } \\
\text { saneamento } \\
\text { básico (CR5) }\end{array}$ & $\begin{array}{l}\text { Auxiliar o gestor no } \\
\text { planejamento dos } \\
\text { gastos públicos. }\end{array}$ & $\begin{array}{c}\text { Verificar a apresentação dos } \\
\text { investimentos por } \\
\text { componente do saneamento } \\
\text { básico. }\end{array}$ & $\begin{array}{l}\text { Dificulta a alocação dos } \\
\text { recursos para cada área } \\
\text { pelos gestores } \\
\text { municipais. }\end{array}$ \\
\hline $\begin{array}{l}\text { Detalhamento } \\
\text { das fontes de } \\
\text { financiamento } \\
\text { dos } \\
\text { investimentos } \\
\text { (CR6) }\end{array}$ & $\begin{array}{l}\text { Nortear os gestores } \\
\text { na busca das fontes } \\
\text { de recursos para } \\
\text { execução das } \\
\text { ações/projetos/progra } \\
\text { mas propostos. }\end{array}$ & $\begin{array}{c}\text { Apurar se as fontes de } \\
\text { financiamento sugeridas } \\
\text { estão de acordo com o } \\
\text { escopo das } \\
\text { ações/projetos/programas e } \\
\text { se todas as possibilidades } \\
\text { estão sendo apresentadas. }\end{array}$ & $\begin{array}{l}\text { Busca por recursos em } \\
\text { fontes financiadoras que } \\
\text { não atendem às } \\
\text { finalidades das ações, } \\
\text { dificultando/ delongando } \\
\text { a obtenção do recurso. }\end{array}$ \\
\hline
\end{tabular}

Fonte: Própria (2016). 


\section{Equação 1 - Expressão do Índice de Conformidade (IC)}

$$
I C=\frac{\sum_{i=1}^{6}\left(P_{i} x A_{i}\right)}{\sum_{i=1}^{6} P_{i}}
$$

Foram definidos pesos $(\mathrm{P})$ de acordo com 0 grau de hierarquização dado pelos especialistas, variando de 1 para o critério menos impactante e crescendo até atingir a importância de 6, destinado ao critério mais impactante.

Os valores possíveis para a pontuação quanto à avaliação dos planos $(\mathrm{A})$ à luz de cada critério foram definidos como: não consta pontuação zero, muito insatisfatório - pontuação 1 , insatisfatório - pontuação 2, pouco satisfatório - pontuação 3, satisfatório - pontuação 4 e muito satisfatório - pontuação 5 .
$\mathrm{P}_{\mathrm{i}}$ - peso de cada critério;

$\mathrm{A}_{\mathrm{i}}$ - pontuação referente à avaliação do plano em cada critério.

Tabela 1 - Exemplo de valores possíveis para o Índice de Conformidade (IC)

\begin{tabular}{|c|c|c|c|c|c|c|c|c|}
\hline \multirow{4}{*}{ Município } & \multicolumn{6}{|c|}{ Avaliação dos planos em cada critério (A) } & \multirow{4}{*}{ - IC } & \multirow{4}{*}{$\begin{array}{c}\text { Classificação } \\
\text { qualitativa }\end{array}$} \\
\hline & $\overline{\text { CR1 }}$ & CR2 & CR3 & $\overline{\text { CR4 }}$ & CR5 & CR6 & & \\
\hline & \multicolumn{6}{|c|}{ Peso de cada critério $(\mathrm{P})$} & & \\
\hline & 6 & 5 & 4 & 3 & 2 & 1 & & \\
\hline $\bar{A}$ & 5 & 5 & 4 & 5 & 5 & 5 & 4,8 & Excelente \\
\hline B & 4 & 3 & 4 & 4 & 3 & 4 & 3,7 & Bom \\
\hline C & 4 & 1 & 3 & 0 & 3 & 5 & 2,5 & Regular \\
\hline D & 2 & 1 & 3 & 0 & 2 & 2 & 1,7 & Ruim \\
\hline
\end{tabular}

Fonte: Própria (2016).

\section{RESULTADOS E DISCUSSÃO}

\section{- Municípios estudados}

Com o intuito de obter uma visão geral dos municípios avaliados na pesquisa, foi realizada uma breve caracterização, quando se buscou informações quanto ao porte populacional, índice de acesso aos serviços de abastecimento de água e de esgotamento sanitário e o Índice de Desenvolvimento Humano (IDH). Além dessas informações, buscou-se identificar as fontes de financiamento para a elaboração do $\mathrm{PMSB}^{2}$ de cada município. A Tabela 3 mostra os dados
O IC varia do valor mínimo de zero, quando - Plano não contempla nenhum dos critérios elencados, ao valor máximo de 5 , quando o plano apresenta a presença de todos os critérios de forma muito satisfatória. Com a obtenção do valor de IC para os planos analisados, foi possível realizar a classificação dos mesmos através da pontuação atingida: $\mathrm{IC}=0$ a 2 - ruim; $I C=2,1$ a 3 regular; $\mathrm{IC}=3,1$ a 4 - bom; e $\mathrm{IC}=4,1$ a 5 excelente (Tabela 1). 
- Validação e hierarquização dos critérios

Por meio da pesquisa realizada com o grupo de especialistas, foi possível validar e hierarquizar os critérios pré-selecionados para a construção do Índice de Conformidade das estimativas dos investimentos dos planos. Dos 46 especialistas, 21 aderiram à consulta (46\% do total), sendo $48 \%$ do sexo feminino, $71 \%$ de nível superior; $29 \%$ com título de mestre e $81 \%$ de Engenheiros Sanitarista e Ambiental. Os resultados da pesquisa estão expostos na Tabela 2. Dessa forma, a posição de cada critério dentro da escala considerada foi definida com base na maior ocorrência de votos para sua alocação naquela posição.

Tabela 2 - Resultados da hierarquização proposta pelo grupo de especialistas dos critérios para a construção do Índice de Conformidade das estimativas dos investimentos de PMSB. N=21

\begin{tabular}{c|c|c|c|c}
\hline Critério & Descrição do critério & Escala & $\begin{array}{c}\text { Número } \\
\text { de } \\
\text { indicações }\end{array}$ & $\begin{array}{c}\text { Percentual } \\
\text { de } \\
\text { indicações }\end{array}$ \\
\hline CR01 & Detalhamento das ações propostas & 1 & 12 & $57,0 \%$ \\
\hline CR2 & $\begin{array}{c}\text { Coerência e adequabilidade das referências } \\
\text { empregadas nas estimativas }\end{array}$ & 2 & 8 & $38,0 \%$ \\
\hline CR3 & $\begin{array}{c}\text { Consistência metodológica empregada nas } \\
\text { estimativas dos custos }\end{array}$ & 3 & 10 & $48,0 \%$ \\
\hline CR4 & $\begin{array}{c}\text { Descrição e coerência dos investimentos ao } \\
\text { longo do horizonte de planejamento }\end{array}$ & 4 & 7 & $33,0 \%$ \\
\hline CR5 & $\begin{array}{c}\text { Delineamento dos investimentos por } \\
\text { componente do saneamento básico }\end{array}$ & 5 & 9 & $43,0 \%$ \\
\hline CR6 & $\begin{array}{c}\text { Detalhamento das fontes de financiamento dos } \\
\text { investimentos }\end{array}$ & 6 & 12 & $57,0 \%$ \\
\hline
\end{tabular}

Fonte: Própria (2016).

- Avaliação dos municípios em cada critério do estudo

Critério 01: Detalhamento das ações dos projetos propostos

A avaliação dos planos quanto ao detalhamento das ações dos projetos propostos (CR01) apresentou como valor mais recorrente a pontuação 4, classificada como satisfatória, abarcando 10 PMSB com essa nota, são eles: São Gabriel do Oeste-MS, Bela Vista de GoiásGO, Alto Araguaia-MG, Barbalha-CE, Rio ClaroSP, Diadema-SP, Rio Grande-RS, Garopaba-SC e Guaraciaba-SC. Porém, a média total dos planos analisados foi da ordem de 3 , classificada como pouco satisfatória.

A nota mínima (1), qualificada como muito insatisfatória, foi obtida por 6 dos PMSB avaliados, pertencendo eles aos municípios de Anori-AM, Careiro-AM, Iranduba-AM, Monte Carmelo-MG, São José dos Campos-SP e Miguel Pereira-RJ.

Todos os planos analisados apresentaram a presença do CR01, ou seja, nenhum deles apresentou pontuação nula nesse quesito.

A análise geral dos planos à luz do CR1 proporcionou a percepção de demasiada confusão com relação aos conceitos de programa, projeto e ação. O exame dos termos de referência da Fundação Nacional de Saúde (FUNASA) e do Ministério das Cidades (MCIDADES) mostra que os programas visam à concretização dos objetivos propostos no PMSB para sanar as deficiências identificadas, especificando um tema foco para o estabelecimento de projetos e ações. Os projetos constituem um conjunto de atividades e operações a serem desenvolvidas, que levam em consideração os recursos disponíveis e o tempo limite para execução. $E$ as ações são desdobramentos do projeto em forma de etapas, que devem ser executadas para atingir os objetivos traçados em horizontes temporais.

Nesse contexto, diversos PMSB analisados apresentaram projetos independentes, sem nenhuma relação entre si, além da falta de contextualização quanto aos seus objetivos, 
metas e horizontes de implementação. Por exemplo, no Plano do município Senador Canedo-GO, foram propostas intervenções nos sistemas de abastecimento de água e de esgotamento sanitário, de forma pontual, sem que estivessem ligadas a um objetivo ou meta ou, ainda, a ações integrantes de programas e projetos.

Percebeu-se, também, que alguns dos planos apresentaram ações pouco detalhadas, nos quais não se especificavam, por exemplo, a população ou as localidades contempladas. Nesse caso se enquadram, por exemplo, os planos dos municípios de Joaquim Távora-PR, Miguel Pereira-RJ e Sinop-MT.

Os PMSB dos municípios de Anori-AM, Careiro-AM e Iranduba-AM não apresentaram descrição das ações dos programas e projetos propostos, se restringindo, ainda, a tratar os projetos de maneira genérica, denominando-os de 'Obras lineares' ou 'Obras localizadas', porém, sem maior descrição do que se trata essa definição, além de não especificar a população contemplada ou as localidades de implantação das obras mencionadas.

Diante do exposto, a maioria dos planos analisados apresentou deficiência no detalhamento das ações dos projetos propostos (CR1). Esse resultado, possivelmente, implicará em projetos e programas que não alcançam seus objetivos e metas, prejudicando, assim, o alcance da universalização do acesso aos serviços públicos de saneamento básico.

Critério 02: Coerência e adequabilidade das referências empregadas nas estimativas

A ampla maioria dos planos analisados não apresentou coerência e adequabilidade das referências empregadas nas estimativas dos investimentos (CR2), ou seja, obtiveram pontuação nula nesse quesito. Houve $20 \mathrm{PMSB}$ contemplados com essa pontuação, representando $80 \%$ dos planos analisados.

A maior pontuação conseguida pelos planos analisados foi no valor de 3 , classificada como pouco satisfatória, e atingida por apenas 3 planos, pertencentes aos municípios de AltaneiraCE, de Barbalha-CE e de Rio Grande-RS. Esses planos citaram as fontes empregadas, porém, para apenas algumas das estimativas de investimentos realizadas.

O Plano do município de Joaquim Távora-PA apresentou pontuação mínima (valor igual a 1), enquadrada como muito insatisfatória. Avaliação foi motivada pela citação das fontes empregadas nas estimativas, porém, sem detalhamento de quais valores foram empregados nos cálculos.

A percepção geral a respeito do CR2 permitiu observar que a maioria dos planos não reserva muito zelo à citação e descrição das referências empregadas nas estimativas de investimentos. Os planos em que as mesmas foram apresentadas se restringiram apenas à sua menção, sem maior detalhamento referente à adequabilidade do uso ao município em questão.

A omissão das fontes consideradas implica diretamente na credibilidade do valor apresentado ao gestor municipal e aos membros da comunidade, não havendo a possibilidade de avaliar se a fonte em que se baseou a estimativa é confiável e se a mesma está de acordo com a realidade local.

A principal consequência do uso de referências não confiáveis é a estimativa de investimentos de ações com custos não compatíveis à sua exequibilidade, impossibilitando a implantação adequada do PMSB e o alcance da universalização do acesso aos serviços públicos de saneamento básico.

\section{Critério 03: Consistência metodológica empregada nas estimativas dos custos}

Semelhante ao critério anterior, a consistência metodológica empregada nas estimativas dos custos dos planos analisados (CR3) apresentou baixa presença nos planos analisados, constando em apenas 3 PMSB e representando $12 \%$ dos PMSB analisados.

Vale ressaltar, entretanto, que mesmo os planos que apresentaram o critério no seu conteúdo, o fizeram de forma pouco detalhada e somente para algumas das estimativas de investimentos. Nenhum dos planos analisados apresentou memorial de cálculo contemplando a metodologia empregada para estimativa de todos os custos das ações previstas.

A maior valoração alcançada para esse critério foi 3 , qualificada como pouco satisfatória, e alcançada apenas pelo município de BarreirasBA. Esse plano apresentou a metodologia de cálculo de algumas das estimativas realizadas, com apresentação dos custos unitários envolvidos e da população contemplada nas ações. 
Tabela 3 - Informações sobre o PMSB dos municípios analisados no estudo

\begin{tabular}{|c|c|c|c|c|c|c|c|}
\hline Região & Estado & Município & $\begin{array}{c}\text { População } \\
\text { estimada em } \\
2016^{1}\end{array}$ & $\begin{array}{c}\text { Índice de acesso } \\
\text { aos serviços de } \\
\text { abastecimento de } \\
\text { água }^{2}\end{array}$ & $\begin{array}{l}\text { Índice de acesso } \\
\text { aos serviços de } \\
\text { esgotamento } \\
\text { sanitário² }\end{array}$ & $\mathrm{IDH}^{3}$ & Órgão Financiador 4 \\
\hline Centro-Oeste & Mato Grosso do Sul & São Gabriel do Oeste & 24.852 & $86 \%{ }^{*}$ & $32 \% *$ & 0,751 & Funasa \\
\hline Centro-Oeste & Goiás & Senador Canedo & 102.947 & $81 \% *$ & $1 \% *$ & 0,701 & Não informado \\
\hline Centro-Oeste & Mato Grosso & Alto Araguaia & 17.841 & $100 \%$ & $5 \%$ & 0,704 & Não informado \\
\hline Centro-Oeste & Goiás & Bela Vista de Goiás & 28.077 & $99 \%$ & $99 \%$ & 0,803 & Não informado \\
\hline Centro-Oeste & Mato Grosso & Sinop & 132.934 & $100 \%$ & $67 \%$ & 0,749 & Não informado \\
\hline Nordeste & Ceará & Altaneira & 7.413 & $100 \%$ & $44 \%$ & 0,729 & Funasa \\
\hline Nordeste & Ceará & Barbalha & 59.343 & $100 \%$ & $68 \%$ & 0,712 & Funasa \\
\hline Nordeste & Bahia & Barreiras & 155.519 & $91 \%{ }^{*}$ & $15 \% *$ & 0,557 & Não informado \\
\hline Nordeste & Bahia & Itabuna & 220.386 & $100 \%$ & $68 \%$ & 0,561 & MCidades \\
\hline Nordeste & Piauí & Teresina & 847.430 & $94 \%$ & $19 \%$ & 0,751 & MCidades \\
\hline Norte & Pará & Joaquim Távora & 11.639 & $98 \%$ & $78 \%$ & 0,7 & Não informado \\
\hline Norte & Pará & Belém & 1.446 .042 & $91 \%$ & $13 \%$ & 0,746 & Não informado \\
\hline Norte & Amazonas & Anori & 19.749 & $100 \%$ & $21 \%$ & 0,721 & Funasa \\
\hline Norte & Amazonas & Careiro & 36.922 & $96 \%$ & $84 \%$ & 0,728 & Funasa \\
\hline Norte & Amazonas & Iranduba & 46.703 & $59 \%$ & $7 \%$ & 0,602 & Funasa \\
\hline Sudeste & São Paulo & Carapicuíba & 394.465 & $59 \%$ & $7 \%$ & 0,683 & Não informado \\
\hline Sudeste & São Paulo & Rio Claro & 201.473 & $100 \%$ & $96 \%$ & 0,807 & Governo do Estado \\
\hline Sudeste & São Paulo & Diadema & 415.180 & $100 \%$ & $94 \%$ & 0,757 & MCidades \\
\hline Sudeste & Rio de Janeiro & Miguel Pereira & 24.855 & $100 \%$ & $46 \%$ & 0,745 & AGEVAP (Comitê de Bacia) \\
\hline Sudeste & Minas Gerais & Monte Carmelo & 48.096 & $96 \%$ & $84 \%$ & 0,613 & Funasa \\
\hline Sudeste & São Paulo & São José dos Campos & 695.992 & $97 \% *$ & $91 \% *$ & 0,753 & Não informado \\
\hline Sul & Rio Grande do Sul & Rio Grande & 208.641 & $90 \%$ & $25 \%$ & 0,744 & Fontes próprias \\
\hline Sul & Santa Catarina & Guaraciaba & 10.316 & $72 \%{ }^{*}$ & $6 \%{ }^{*}$ & 0,479 & Funasa \\
\hline Sul & Santa Catarina & Garopaba & 21.573 & $75 \% *$ & $0,3 \% *$ & 0,574 & Não informado \\
\hline Sul & Rio Grande do Sul & Ibirubá & 20.300 & $84 \% *$ & $1 \%{ }^{*}$ & 0,765 & Funasa \\
\hline
\end{tabular}

* Para esses municípios são mostrados dados do IBGE 2010, pois o Snis não dispunha de informações sobre os mesmos.

Fonte: ${ }^{1}$ IBGE (2016)2; BRASIL/SNIS (2014)3; IBGE (2014)4; PMSB de cada município. 
Os planos dos municípios de Senador Canedo-GO e Rio Claro-SP apresentaram pontuação 2 - insatisfatória, para o CR3. Avaliação motivada pela citação de apenas alguns dos custos unitários envolvidos nas estimativas de investimentos apresentadas no Plano.

A consistência metodológica empregada nas estimativas dos investimentos influencia na credibilidade e validade dos custos apresentados, comprometendo a exequibilidade dos planos apresentados para os gestores e membros da comunidade.

A omissão das ponderações envolvidas na estimativa dos custos para execução do plano demonstra negligência por parte dos elaboradores e dos órgãos e comitês fiscalizadores da elaboração do Plano.

Critério 04: Descricão e coerência dos investimentos ao longo do horizonte de planejamento

Quanto à descrição e coerência dos investimentos ao longo do horizonte de planejamento (CR4), a pontuação de maior ocorrência foi o valor de 3 - pouco satisfatória, sendo apresentada por 11 planos analisados, representando $44 \%$ do total. Porém, a pontuação média total dos planos no CR4 apresentou valor na importância de 2, classificada como insatisfatória.

Houve ausência do critério em 6 PMSB analisados, sendo eles pertencentes aos municípios de Sinop-MS, Bela Vista de GoiásGO, Alto Araguaia-MT, Monte Carmelo-MG, São José dos Campos-SP e Ibirubá-RS. Nesses planos, foi apresentado o valor total para cada programa e projeto, porém, não houve detalhamento do horizonte de implantação dos mesmos e, ainda, do valor de investimento necessário a cada horizonte de execução do Plano.

A avaliação máxima, correspondente ao valor 5 - muito satisfatória, foi alcançada apenas pelo Plano do município de Rio Grande-RS, em que houve apresentação do horizonte de implantação de todas as ações propostas e coerência na definição do horizonte temporal das ações inter-relacionadas.

A maioria dos planos analisados define horizontes temporais para implantação das ações, como orientam os termos de referência da
Funasa e do MCidades. Isto é, definem, por exemplo, que 0 horizonte emergencial corresponde de 1 a 2 anos da elaboração do Plano, o horizonte de curto prazo de 3 a 5 anos, e o mesmo raciocínio é aplicado para os horizontes de médio e longo prazo.

A descrição dos investimentos ao longo do horizonte de planejamento, na maioria dos PMSB analisados, foi feita seguindo os horizontes temporais definidos; porém, se restringiram apenas a essa forma de apresentação, não demonstrando a alocação dos investimentos ano a ano, como, por exemplo, os planos dos municípios de São Gabriel do Oeste-MS, Senador Canedo-GO, Altaneira-CE e Barbalha-CE.

A omissão da descrição dos investimentos ao longo do horizonte de planejamento dificulta a previsão dos gastos públicos por parte dos gestores municipais, influenciando nas alocações nos planos plurianuais e delongando a implantação do PMSB.

\section{Critério 05: Delineamento dos investimentos por componente do saneamento básico}

No que se refere ao delineamento dos investimentos por componente do saneamento básico, o valor de maior ocorrência foi 4 satisfatória, abarcando 7 PMSB. Porém, a pontuação média dos planos analisados no CR5 alcançou o valor de 2, qualificada como insatisfatória.

Cinco planos analisados não apresentaram o delineamento referido (CR5), sendo eles pertencentes aos municípios de Bela Vista de Goiás-GO, Alto Araguaia-MT, Monte CarmeloMG, Rio Claro-SP e São José dos Campos-SP. Esses planos apresentaram apenas a descrição dos valores dos seus programas e projetos, sem apresentar o valor total referente ao investimento necessário para cada componente do saneamento básico.

A pontuação máxima atingida pelos planos foi de 4 - satisfatória, e apresentada pelos municípios de São Gabriel do Oeste-MS, ItabunaBA, Altaneira-CE, Barbalha-CE, Carapicuíba-SP, Rio Grande-RS e Guaraciaba-SC. Em comum, esses planos apresentaram o total referente ao investimento necessário para cada componente do saneamento básico em cada horizonte de planejamento definido. Porém, não apresentaram o valor anual de investimento necessário para as mesmas. 
A valoração mínima (1 - muito insatisfatória) foi abarcada por 2 PMSB analisados, sendo eles pertencentes aos municípios de Belém-PA e lbirubá-RS. Ambos os planos apresentaram apenas os custos envolvidos na execução de cada projeto previsto no Plano, sem apresentação do investimento total necessário para as componentes do saneamento básico.

A omissão da apresentação dos investimentos necessários a cada componente do saneamento básico dificulta a alocação dos recursos pelos gestores municipais e, ainda, a busca por financiamentos para execução das ações do Plano, obstaculizando o alcance da universalização do acesso aos serviços públicos de saneamento básico.

Critério 06: Detalhamento das fontes de financiamento dos investimentos

O detalhamento das fontes de financiamento dos investimentos (CR6) apresentou ausência em 12 planos analisados, correspondendo a $48 \%$ do total. A pontuação mais recorrente e a pontuação média dos planos no CR6 obtiveram avaliação no valor 1 - muito insatisfatória.

A avaliação máxima, no valor de 5 - muito satisfatória, foi alcançada apenas pelo PMSB do município de Guaraciaba-SC, em que foram descritas e detalhadas as possíveis fontes de financiamentos nas esferas federal, estadual e municipal, além de apresentar a possibilidade de atuação de cada uma nos projetos e programas propostos no Plano.

Os municípios de São Gabriel do Oeste-MS, Altaneira-CE, Barbalha-CE, Teresina-PI e Garopaba-SC apresentaram e descreveram, brevemente, as possíveis fontes de financiamento, porém, sem relacionar com os programas e projetos propostos; por isso, obtiveram pontuação 3 para o presente critério.

A observação dos planos permitiu verificar que a grande maioria não apresenta de forma satisfatória as possíveis fontes de financiamento para as ações de saneamento básico.

A principal implicação da deficiência de apresentação do CR6 está relacionada ao alcance dos financiamentos necessários à execução do PMSB. Sabe-se que a grande maioria dos municípios brasileiros é de pequeno porte, onde há uma carência quanto à capacidade do corpo técnico das prefeituras e, sendo assim, há muito desconhecimento a respeito dos órgãos governamentais de atuação no saneamento básico. A função do Plano é, também, de esclarecer e expor todas as possíveis fontes de financiamento para sua execução, como forma de facilitar a busca por recursos pelos gestores municipais.

\section{- Avaliação pelo Índice de Conformidade}

Com base na pontuação alcançada pelos PMSB analisados em cada critério supracitado, foi possível obter valoração para o Índice de Conformidade (IC). O resultado obtido por cada Plano analisado para 0 IC classifica-o qualitativamente nas categorias: 'ruim', 'regular', 'bom' e 'excelente'. A Tabela 4 mostra a pontuação dos planos analisados no estudo em cada critério e os resultados alcançados para o IC.

A observação dos dados expostos na Tabela 4 mostra que 17 PMSB analisados apresentaram valor para o IC abaixo de 2, sendo classificados como ruins. Sete obtiveram notas entre 2,1 e 3 , sendo qualificados como regulares. Apenas 1 plano apresentou valoração para o IC entre 3,1 e 4 , sendo enquadrado como bom. E nenhum plano alcançou pontuação acima de 4,1 para o IC, ou seja, não houve plano classificado como excelente na análise realizada. A Figura 1 mostra o resultado global da amostra analisada.

A análise dos dados apresentados na Figura 1 demonstra o baixo grau de comprometimento do Poder Público com o planejamento das ações de saneamento básico, refletindo em instrumentos da gestão municipal com qualidade precária. Esse resultado já era esperado, devido ao histórico brasileiro em minimizar, ou mesmo eximir, a importância do planejamento dos serviços públicos para o sucesso da sua execução. A Figura 2 ilustra os resultados obtidos de modo a deixar clara a posição ocupada por cada plano avaliado com base na pontuação obtida para o IC.

Em seguida, foi feita uma análise dos municípios enquadrados em cada categoria definida para o IC, além de ser discutido o desempenho dos municípios em cada região do País.

\section{- Municípios com planos qualificados como ruins}

Os dezessete planos qualificados como ruins apresentam características distintas entre si, estando presentes municípios de pequeno, médio 
e grande porte populacional. Entre estes, apenas os municípios de Iranduba-AM e Garopaba-SC apresentaram índices de acesso aos serviços públicos de abastecimento de água inferiores à média nacional de $80 \%$, ou seja, a grande maioria dos municípios apresenta índice superior ao nacional, sendo presentes ainda municípios em que há universalização do acesso à água (BRASIL, 2014).

\section{Figura 1 - Qualificação dos PMSB analisados de acordo com a pontuação obtida para o Índice de Conformidade}

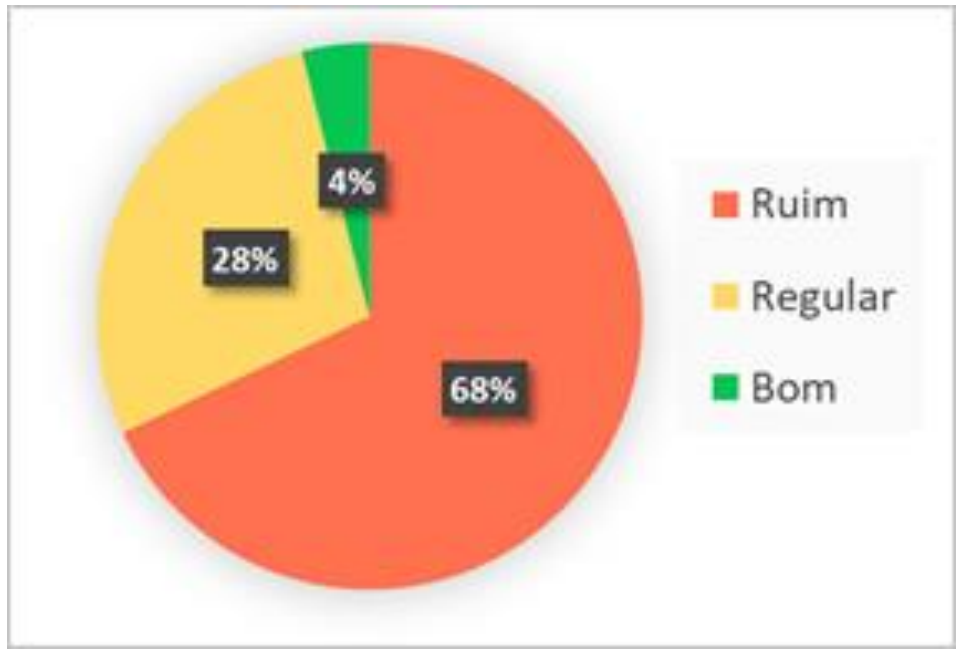

Fonte: Própria (2016).

Figura 2 - Índices de Conformidade das estimativas de investimentos dos PMSB analisados. 2016

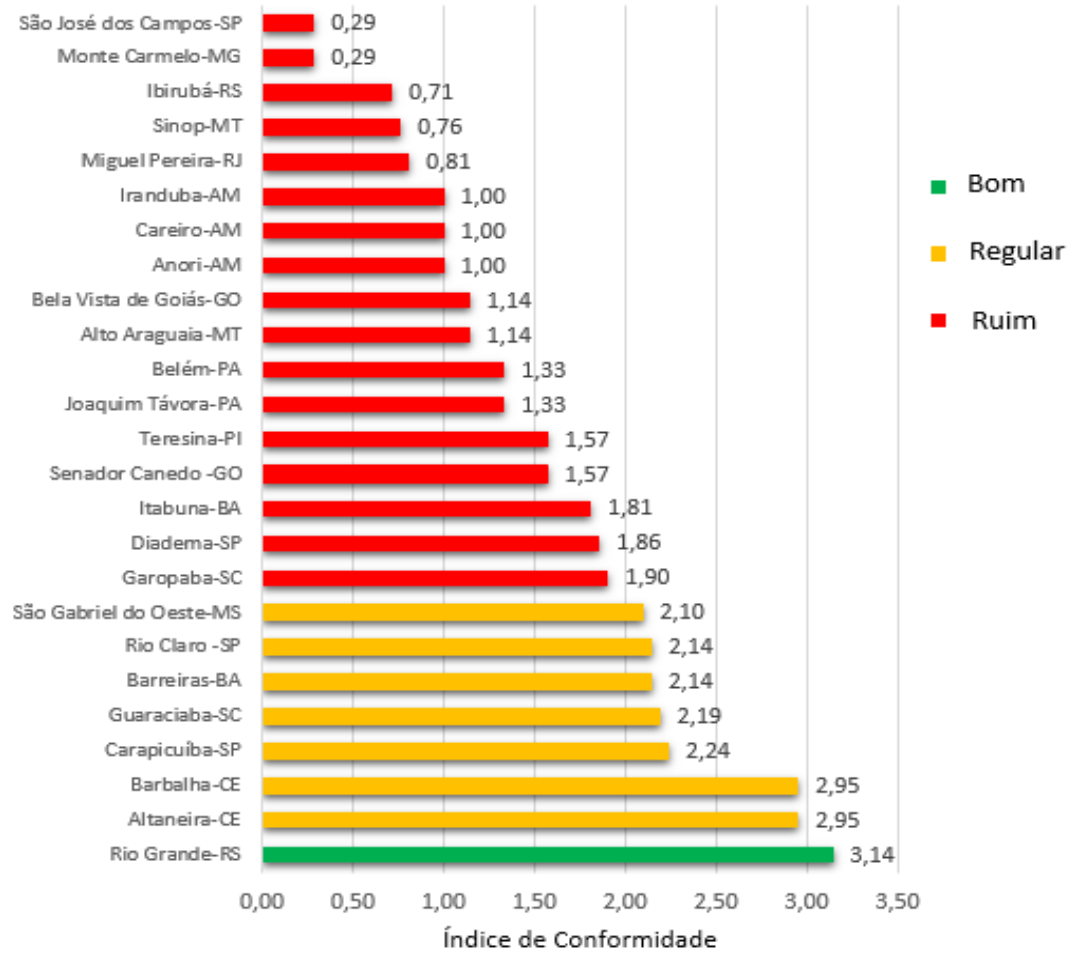

Fonte: Própria (2016). 
Tabela 4 - Avaliação dos PMSB em cada critério e resultado do Índice de Conformidade

\begin{tabular}{|c|c|c|c|c|c|c|c|c|c|c|}
\hline \multirow{2}{*}{ Região } & \multirow{2}{*}{ Estado } & \multirow{2}{*}{ Município } & \multicolumn{6}{|c|}{ Análise dos planos em cada critério (A) } & \multirow{2}{*}{ IC } & \multirow{2}{*}{$\begin{array}{c}\text { Classificação do } \\
\text { IC }\end{array}$} \\
\hline & & & CR01 & CR02 & CR03 & CR04 & CR05 & CR06 & & \\
\hline Centro-oeste & Mato Grosso & Sinop & 2 & 0 & 0 & 0 & 2 & 0 & 0,8 & Ruim \\
\hline Centro-oeste & Mato Grosso do Sul & São Gabriel do Oeste & 4 & 0 & 0 & 3 & 4 & 3 & 2,1 & Regular \\
\hline Centro-oeste & Goiás & Bela Vista de Goiás & 4 & 0 & 0 & 0 & 0 & 0 & 1,1 & Ruim \\
\hline Centro-oeste & Mato Grosso & Alto Araguaia & 4 & 0 & 0 & 0 & 0 & 0 & 1,1 & Ruim \\
\hline Centro-oeste & Goiás & Senador Canedo & 2 & 0 & 2 & 3 & 2 & 0 & 1,6 & Ruim \\
\hline Nordeste & Bahia & Barreiras & 3 & 0 & 3 & 3 & 3 & 0 & 2,1 & Regular \\
\hline Nordeste & Bahia & Itabuna & 3 & 0 & 0 & 4 & 4 & 0 & 1,8 & Ruim \\
\hline Nordeste & Ceará & Altaneira & 4 & 3 & 0 & 4 & 4 & 3 & 3,0 & Regular \\
\hline Nordeste & Ceará & Barbalha & 4 & 3 & 0 & 4 & 4 & 3 & 3,0 & Regular \\
\hline Nordeste & Piauí & Teresina & 3 & 0 & 0 & 2 & 3 & 3 & 1,6 & Ruim \\
\hline Norte & Amazonas & Anori & 1 & 0 & 0 & 3 & 3 & 0 & 1,0 & Ruim \\
\hline Norte & Amazonas & Careiro & 1 & 0 & 0 & 3 & 3 & 0 & 1,0 & Ruim \\
\hline Norte & Amazonas & Iranduba & 1 & 0 & 0 & 3 & 3 & 0 & 1,0 & Ruim \\
\hline Norte & Pará & Belém & 2 & 0 & 0 & 4 & 1 & 2 & 1,3 & Ruim \\
\hline Norte & Pará & Joaquim Távora & 2 & 1 & 0 & 2 & 2 & 1 & 1,3 & Ruim \\
\hline Sudeste & Minas Gerais & Monte Carmelo & 1 & 0 & 0 & 0 & 0 & 0 & 0,3 & Ruim \\
\hline Sudeste & São Paulo & Rio Claro & 4 & 0 & 2 & 3 & 0 & 4 & 2,1 & Regular \\
\hline Sudeste & São Paulo & Carapicuíba & 3 & 2 & 0 & 3 & 4 & 2 & 2,2 & Regular \\
\hline Sudeste & São Paulo & Diadema & 4 & 0 & 0 & 3 & 3 & 0 & 1,9 & Ruim \\
\hline Sudeste & São Paulo & São José dos Campos & 1 & 0 & 0 & 0 & 0 & 0 & 0,3 & Ruim \\
\hline Sudeste & Rio de Janeiro & Miguel Pereira & 1 & 0 & 0 & 2 & 2 & 1 & 0,8 & Ruim \\
\hline Sul & Rio Grande do Sul & Rio Grande & 4 & 3 & 0 & 5 & 4 & 4 & 3,1 & Bom \\
\hline Sul & Santa Catarina & Garopaba & 4 & 0 & 0 & 3 & 2 & 3 & 1,9 & Ruim \\
\hline Sul & Santa Catarina & Guaraciaba & 4 & 0 & 0 & 3 & 4 & 5 & 2,2 & Regular \\
\hline Sul & Rio Grande do Sul & Ibirubá & 2 & 0 & 0 & 0 & 1 & 1 & 0,7 & Ruim \\
\hline
\end{tabular}

Fonte: Própria (2016). 
O acesso aos serviços públicos de esgotamento sanitário apresentou significativa variabilidade entre os índices apresentados pelos municípios, existindo locais com cobertura de apenas $0,3 \%$ até locais com $99 \%$ de cobertura. Quanto ao IDH, a maioria dos municípios apresenta valor superior à média nacional de 0,699 (IBGE, 2010), com índices variando de 0,479 a 0,807 .

Diante das características tão distintas apresentadas pelos municípios enquadrados como ruins na avaliação do IC, não foi possível traçar um perfil que justifique essa classificação, sendo necessário um aprofundamento maior para obter clareza a respeito dos fatores que influenciam a elaboração do PMSB.

\section{- Municípios com planos qualificados como regulares}

Os sete PMSB enquadrados como regulares são pertencentes a municípios de pequeno e de médio porte populacional, sendo eles: Carapicuíba-SP, Guaraciaba-SC, São Gabriel do Oeste-MS, Rio Claro-SP, Barreiras-BA, AltaneiraCE e Barbalha-CE. Apenas os municípios de Rio Claro-SP e Barbalha-CE apresentam índices de acesso aos serviços públicos de abastecimento de água e de esgotamento sanitário acima da média nacional, possuindo, ainda, valores de IDH superiores ao IDH do País $(0,699)$. Os demais municípios apresentam algum dos índices citados com valor inferior à média nacional.

Sendo assim, o levantamento dos dados municipais da maioria dos planos enquadrados como regulares demonstra uma baixa estruturação municipal quanto à prestação dos serviços públicos de saneamento básico. Esse fator possivelmente tem relação com a baixa qualidade dos instrumentos de planejamento relacionados à área da gestão pública municipal.

\section{- Municípios com planos qualificados como bons}

Apenas o município do Rio Grande, pertencente ao Estado do Rio Grande do Sul, apresentou PMSB qualificado como bom, segundo a metodologia de avaliação do IC. Esse município apresenta elevado índice de acesso da população aos serviços públicos de abastecimento de água (90\%) e baixo índice de cobertura dos serviços de esgotamento sanitário (25\%). O IDH do município $(0,744)$ é superior ao média brasileira $(0,699)$, possuindo porte populacional médio.

Possivelmente o porte populacional médio do Município, característica que geralmente possui relação com o grau de estruturação do corpo técnico das prefeituras, influenciou o resultado obtido. Prefeituras melhor estruturadas possuem maior capacidade técnica para fiscalização e participação do processo de elaboração do Plano. Porém, como os resultados para essa classificação foram escassos, não é possível traçar uma relação segura entre as características municipais o desempenho no IC.

\section{- Municípios com planos qualificados como excelentes}

Não houve municípios classificados como excelentes na análise realizada.

\section{- Análise do desempenho dos municípios no IC considerando a região do Brasil}

Conforme demonstrado nos dados discutidos, todos os planos pertencentes a municípios da região Norte do País foram classificados como ruins com base no valor obtido para o IC. A região Centro-Oeste apresentou apenas 1 PMSB enquadrado como regular (São Gabriel do Oeste-GO), tendo os demais a classificação de ruins. Essas regiões são marcadas por um nível de desenvolvimento urbano baixo, alto deficit de cobertura dos serviços públicos de saneamento básico, além de baixo nível de estruturação do corpo técnico das prefeituras, o que, possivelmente, influenciou os resultados apresentados no estudo.

A região Sudeste apresentou planos classificados como regulares (2) e ruins (4). Esses resultados surpreendem devido ao elevado grau de desenvolvimento apresentado pela região, refletido em altos índices de acesso aos serviços públicos de saneamento básico e, ainda, devido ao aporte de recursos destinados pela União para essa região ser historicamente superior às demais.

A região Sul apresentou resultados bem variados, com presença de municípios com planos enquadrados nas categorias ruim (2), regular (1) e bom (1). Semelhante à região Sudeste, a região Sul do País apresenta índices de acesso aos serviços públicos de saneamento básico elevados, além de também possuir alto 
nível de desenvolvimento urbano. Logo, era de se esperar que apresentasse desempenho mais satisfatório.

A possível explicação para o desempenho apresentado pelos planos dos municípios de ambas as regiões está guardada no fato de o saneamento básico já não ser prioridade para 0 Poder Público local, devido aos elevados níveis de acesso aos seus serviços, configurando uma realidade menos preocupante em relação ao restante do País.

Apesar das regiões Sul e Sudeste apresentarem, quantitativamente, maior presença de PMSB do que as demais regiões do País (BRASIL, 2016), em termos qualitativos, os planos apresentam desempenho precário na etapa avaliada no presente estudo.

A região Nordeste apresentou municípios com planos enquadrados nas categorias ruim (2) e regular (4). O índice de cobertura por abastecimento de água nesses municípios é bastante satisfatório, com valores entre $91 \%$ e $100 \%$; porém, a cobertura por esgotamento sanitário apresentou oscilação considerável, com valores entre $15 \%$ e $68 \%$ de acesso.

Os municípios avaliados apresentaram, ainda, porte populacional classificado em pequeno (1), médio (4) e grande (1). A presença majoritária de municípios de porte médio pode ter influenciado no desempenho dos planos analisados, uma vez que esses municípios apresentam melhor estruturação do corpo técnico das prefeituras, possibilitando maior participação e influência no processo de elaboração do PMSB.

Dados da pesquisa do IBGE sobre Perfil dos Municípios Brasileiros de 2014 revelaram que os municípios com população maior que 50.000 habitantes dispunham de mais de $20 \%$ dos gestores com pós-graduação, ao passo que nos menores municípios (população menor que 50.000 ) esse indicador era de $6,6 \%$. Por outro lado, a mesma pesquisa revelou que a média de funcionários da administração direta dos municípios com população entre 20.000 a 50.000 habitantes era de 2.437 , já nos municípios entre 50.000 e 100.000 chegou a 4.232. Embora não seja possível estabelecer uma relação direta entre esses indicadores com uma melhor capacidade técnica dos municípios de porte médio, certamente eles apontam para essa direção.

Sendo assim, com base nos resultados, nota-se que a região Nordeste apresentou melhor desempenho quanto à avaliação da metodologia empregada nas estimativas de investimentos para execução dos PMSB (Tabela 5), comparada às demais regiões.

De uma forma geral, pode-se sugerir que os resultados pouco satisfatórios das estimativas de investimentos dos PMSB devem-se a duas questões principais. A primeira relaciona-se à falta de política pública orientada para o fortalecimento do Poder Público local e de sua correspondente capacidade de responder às demandas e necessidades de seus territórios. Tal questão relaciona-se às fragilidades do pacto federativo brasileiro que, a despeito da ordem constitucional que elege os municípios como protagonistas de políticas públicas essenciais como o planejamento urbano, a moradia, a educação, a saúde, o saneamento básico, a mobilidade urbana - não promove a divisão justa dos tributos entre os entes federados, o que deixa os municípios mais vulneráveis e incapazes para fazer frente às suas prerrogativas legais e às necessidades dos munícipes.

A segunda questão, que tem vínculo com a primeira, diz respeito à posição marginal que as políticas setoriais, com destaque para as de saneamento básico, assumem frente às estratégias municipais. Via de regra, os municípios dispõem de um plano diretor elaborado de forma precária sob forte exigência do governo federal, sem que este instrumento da política urbana se constitua um real indutor do desenvolvimento urbano municipal. A desqualificação da política pública e de seus instrumentos, como os planos, é uma regra nos municípios brasileiros, embalada pela alternância de poder e pela incapacidade técnica e de gestão das prefeituras municipais. Assim, os males dos PMSB são os males das políticas públicas municipais e de seus respectivos instrumentos a exemplo dos planos.

\section{CONCLUSÃO}

O estudo desenvolvido cumpriu o objetivo geral proposto de analisar criticamente a metodologia empregada nas estimativas de investimentos de planos municipais de saneamento básico de municípios brasileiros. De forma geral, os planos dos municípios analisados não demonstraram desempenho satisfatório na avaliação realizada. 
Os critérios definidos para análise da metodologia empregada pelos planos foram: detalhamento das ações dos projetos propostos (CR1), coerência e adequabilidade das referências empregadas nas estimativas (CR2), consistência metodológica empregada nas estimativas dos custos (CR3), descrição e coerência dos investimentos ao longo do horizonte de planejamento (CR4), delineamento dos investimentos por componente do saneamento básico (CR5) e detalhamento das fontes de financiamento dos investimentos (CR6).

Tabela 5 - Desempenho do IC dos PMSB analisados por município e por região

\begin{tabular}{|c|c|c|c|c|c|}
\hline Região & Município & $\begin{array}{l}\text { IC por } \\
\text { município }\end{array}$ & $\begin{array}{l}\text { Classificação } \\
\text { do IC por } \\
\text { município }\end{array}$ & $\begin{array}{c}\text { IC } \\
\text { médio } \\
\text { por } \\
\text { região }\end{array}$ & $\begin{array}{l}\text { Classificação } \\
\text { do IC por } \\
\text { região }\end{array}$ \\
\hline \multirow{5}{*}{$\begin{array}{l}\text { Centro- } \\
\text { Oeste }\end{array}$} & São Gabriel do Oeste- & 2,10 & Regular & \multirow{5}{*}{1,34} & \multirow{5}{*}{ Ruim } \\
\hline & Senador Canedo-GO & 1,57 & Ruim & & \\
\hline & Alto Araguaia-MT & 1,14 & Ruim & & \\
\hline & Bela Vista de Goiás-GO & 1,14 & Ruim & & \\
\hline & Sinop-MT & 0,76 & Ruim & & \\
\hline \multirow{5}{*}{ Nordeste } & Altaneira-CE & 2,95 & Regular & \multirow{5}{*}{2,29} & \multirow{5}{*}{ Regular } \\
\hline & Barbalha-CE & 2,95 & Regular & & \\
\hline & Barreiras-BA & 2,14 & Regular & & \\
\hline & Itabuna-BA & 1,81 & Ruim & & \\
\hline & Teresina-PI & 1,57 & Ruim & & \\
\hline \multirow{5}{*}{ Norte } & Joaquim Távora-PA & 1,33 & Ruim & \multirow{5}{*}{1,13} & \multirow{5}{*}{ Ruim } \\
\hline & Belém-PA & 1,33 & Ruim & & \\
\hline & Anori-AM & 1,00 & Ruim & & \\
\hline & Careiro-AM & 1,00 & Ruim & & \\
\hline & Iranduba-AM & 1,00 & Ruim & & \\
\hline \multirow{6}{*}{ Sudeste } & Carapicuíba-SP & 2,24 & Regular & \multirow{6}{*}{1,27} & \multirow{6}{*}{ Ruim } \\
\hline & Rio Claro -SP & 2,14 & Regular & & \\
\hline & Diadema-SP & 1,86 & Ruim & & \\
\hline & Miguel Pereira-RJ & 0,81 & Ruim & & \\
\hline & Monte Carmelo-MG & 0,29 & Ruim & & \\
\hline & São José dos Campos- & 0,29 & Ruim & & \\
\hline \multirow{4}{*}{ Sul } & Rio Grande-RS & 3,14 & Bom & \multirow{4}{*}{1,99} & \multirow{4}{*}{ Ruim } \\
\hline & Guaraciaba-SC & 2,19 & Regular & & \\
\hline & Garopaba-SC & 1,90 & Ruim & & \\
\hline & Ibirubá-RS & 0,71 & Ruim & & \\
\hline
\end{tabular}

Fonte: Própria (2016).

Por meio dos critérios avaliativos, foi possível identificar inconsistências metodológicas nos procedimentos de obtenção das estimativas de investimentos dos planos. A grande maioria dos planos apresentou desempenho insatisfatório em todos os critérios mencionados, refletindo, então, em um comportamento precário para o Índice de Conformidade (IC).

A análise realizada pelo IC classificou $68 \%$ dos planos como ruins, $28 \%$ como regulares e $4 \%$ como bons, sendo a categoria excelente não abarcada por nenhum dos planos estudados.

Os planos qualificados como ruins apresentaram significativa variabilidade quanto às características municipais, não sendo possível traçar um perfil que justifique essa classificação. Evidenciou-se ser necessário um aprofundamento maior para obter clareza a respeito dos fatores que influenciam a elaboração dos PMSB.

Quanto aos planos enquadrados como regulares, o levantamento dos dados municipais demonstrou baixa estruturação quanto à prestação dos serviços públicos de saneamento básico, indicada pelos baixos índices de cobertura dos serviços. Esse fator, possivelmente, possui relação com a baixa qualidade dos planos analisados. 
Apenas o plano do município de Rio Grande, pertencente ao Estado do Rio Grande do Sul, apresentou pontuação para 0 IC que 0 categorizou como bom. Dessa forma, a formulação de uma hipótese que justifique 0 resultado da avaliação é comprometida pela quantidade escassa de dados.

Debruçou-se, ainda, um olhar sobre as regiões do Brasil com relação ao desempenho da metodologia das estimativas de investimentos no IC. A região Nordeste apresentou melhor classificação entre as demais. A principal justificativa para esse comportamento, possivelmente, está guardada na presença majoritária de planos de municípios de médio porte, que, geralmente, apresentam melhor estruturação do corpo técnico das prefeituras, possibilitando maior participação e influência no processo de elaboração do PMSB.

De modo geral, os resultados obtidos no trabalho permitem verificar que a qualidade dos planos elaborados ainda carece de um olhar aprofundado pelo Poder Público municipal, titular do serviço, e pelos órgãos fiscalizadores. Há uma considerável deficiência na metodologia empregada na obtenção das estimativas de investimentos de todos os 25 planos analisados no estudo.

A gestão municipal está diante de grandes desafios para aprimorar as suas políticas e os seus planos municipais de saneamento básico. A melhoria da qualidade de vida da população está diretamente relacionada à superação desses novos desafios impostos.

Para que os princípios fundamentais orientados pela Lei Nacional do Saneamento Básico (Lei n 11.445/2007) sejam atendidos, é necessária a reavaliação da metodologia empregada na elaboração das estimativas de investimentos dos PMSB dos municípios brasileiros.

\section{REFERÊNCIAS}

BARACHO, R. O. Análise e avaliação de Planos Municipais de Saneamento Básico no Paraná: um estudo de caso em cinco cidades. 2015. Trabalho de Conclusão de Curso (Bacharelado em Engenharia Ambiental) - Universidade Tecnológica Federal do Paraná, Londrina, Paraná, 2015.

BRASIL. Lei no 11.445, de 5 de janeiro de 2007. Estabelece diretrizes nacionais para o saneamento básico; altera as Leis $\mathrm{n}^{\mathrm{os}} 6.766$, de 19 de dezembro de 1979, 8.036, de 11 de maio de 1990, 8.666, de 21 de junho de 1993, 8.987, de 13 de fevereiro de 1995; revoga a Lei $n^{\circ} 6.528$, de 11 de maio de 1978; e dá outras providências. Diário Oficial [República Federativa do Brasil], Brasília, DF, 08 de jan. 2007.

\section{Sistema Nacional de Informações sobre}

Saneamento. 2014. Disponível em:
<http://app.cidades.gov.br/serieHistorica/> Acesso em: 09 nov. 2016.

IBGE. Instituto Brasileiro de Geografia e Estatística (Org.). Pesquisa de Informações Básicas Municipais: Perfil dos Municípios Brasileiros. Rio de Janeiro: 2014. Disponível em: $<\mathrm{ftp}: / / \mathrm{ftp}$.ibge.gov.br/Perfil_Municipios/2013/munic2013. pdf>. Acesso em: 09 nov. 2013.

\section{Instituto Brasileiro de Geografia e Estatística \\ 2016. Disponível em: <} http://www.cidades.ibge.gov.br/xtras/home.php> Acesso em: 09 nov. 2016.

MUNARETTO, L. F.; CORRÊA, H. L.; CUNHA, J. A. C. da. Um estudo sobre as características do método Delphi e de grupo focal, como técnicas na obtenção de dados em pesquisas exploratórias. Rev. Adm., UFSM, Santa Maria, v. 6, n. 1, p. 09-24, jan./mar. 2013,

PEREIRA, T. S. T. Conteúdo e metodologia dos Planos Municipais de Saneamento Básico: um olhar para 18 casos No Brasil. 2012. 208f. TCC Especialização em Gestão e Tecnologia do Saneamento, Escola Nacional de Saúde Pública, Fundação Oswaldo Cruz, Brasília, 2012.

SKULMOSKI, G. J.; HARTMAN, F. T.; KRAHN, J. The Delphi method for graduate research. Journal of Information Technology Education, v. 6, n. 6, 2007. 